\title{
Correction to: Atypical evolution of meningiomatosis after discontinuation of cyproterone acetate: clinical cases and histomolecular characterization
}

Thibault Passeri ${ }^{1,2}$ (1) $\cdot$ Lorenzo Giammattei $^{1} \cdot$ Tuan Le Van $^{1} \cdot$ Rosaria Abbritti $^{1}$ - Alexandre Perrier ${ }^{2}$. Jennifer Wong ${ }^{2}$. Christine Bourneix ${ }^{2} \cdot$ Marc Polivka $^{3} \cdot$ Homa Adle-Biassette $^{3} \cdot$ Anne-Laure Bernat $^{1}$ - Julien Masliah-Planchon ${ }^{2}$. Emmanuel Mandonnet ${ }^{1} \cdot$ Sébastien Froelich ${ }^{1}$

Published online: 9 November 2021

(c) Springer-Verlag GmbH Austria, part of Springer Nature 2021

\section{Correction to: Acta Neurochirurgica} https://doi.org/10.1007/s00701-021-05005-9

The correct Table 1 should be the below:

The original article has been corrected.

\begin{tabular}{|c|c|c|c|c|}
\hline & Case 1 & Case 2 & Case 3 & Case 4 \\
\hline Sex & Female & Female & Female & Female \\
\hline $\begin{array}{l}\text { Age at diagnosis } \\
\text { (year) }\end{array}$ & 45 & 62 & 53 & 42 \\
\hline Symptoms & None & None & $\begin{array}{l}\text { Memory } \\
\text { impairment }\end{array}$ & None \\
\hline $\begin{array}{l}\text { Treatment dura- } \\
\text { tion (year) }\end{array}$ & 5 & 22 & 10 & 26 \\
\hline $\begin{array}{l}\mathrm{N}^{\circ} \text { of meningi- } \\
\text { omas }\end{array}$ & 2 & 3 & 2 & 5 \\
\hline \multicolumn{5}{|c|}{ Growing meningiomas } \\
\hline $\mathrm{N}^{\circ}$ of tumors & 1 & 1 & 1 & 1 \\
\hline Location & $\begin{array}{l}\text { Occipital } \\
\text { tentorium }\end{array}$ & $\begin{array}{l}\text { Temporal } \\
\text { convexity }\end{array}$ & $\begin{array}{c}\text { Olfactory } \\
\text { groove }\end{array}$ & Tuberculum \\
\hline $\begin{array}{l}\text { WHO grade } \\
\text { (I/II/III) }\end{array}$ & $\begin{array}{l}\text { Grade I } \\
\text { Fibroblas- } \\
\text { tic }\end{array}$ & $\begin{array}{c}\text { Grade I } \\
\text { Fibro- } \\
\text { blastic }\end{array}$ & $\begin{array}{l}\text { Grade I } \\
\text { Transitional }\end{array}$ & $\begin{array}{l}\text { Grade I } \\
\text { Meningothe- } \\
\quad \text { lial }\end{array}$ \\
\hline PR (low/high $\left.{ }^{1}\right)$ & High & Low & High & High \\
\hline
\end{tabular}

The original article can be found online at https://doi.org/10.1007/ s00701-021-05005-9

Thibault Passeri

thibault.passeri@neurochirurgie.fr

1 Department of Neurosurgery, Lariboisière Hospital, Assistance Publique - Hopitaux de Paris, University of Paris, Paris, France

2 Department of Genetics, Institut Curie, Paris, France

3 Department of Anatomopathology, Lariboisière Hospital, Assistance Publique - Hopitaux de Paris, University of Paris, Paris, France

\begin{tabular}{|c|c|c|c|c|}
\hline & Case 1 & Case 2 & Case 3 & Case 4 \\
\hline $\begin{array}{l}\mathrm{Ki}-67(\%) \\
\quad(\text { low/high } \\
\end{array}$ & Low & High & Low & Low \\
\hline Mutation & $N F 2$ & $N F 2$ & $\mathrm{NC}$ & $\mathrm{NC}$ \\
\hline $\begin{array}{l}\text { Meningeal } \\
\text { embryologi- } \\
\text { cal origin }\end{array}$ & Neural crest & Neural crest & $\begin{array}{l}\text { Paraxial } \\
\text { mesoderm }\end{array}$ & $\begin{array}{l}\text { Paraxial } \\
\text { mesoderm }\end{array}$ \\
\hline \multicolumn{5}{|c|}{ Shrinking meningiomas } \\
\hline $\mathrm{N}^{\circ}$ of tumors & 1 & 2 & 1 & 4 \\
\hline Location & $\begin{array}{l}\text { Frontal } \\
\text { convexity }\end{array}$ & $\begin{array}{l}\text { Spheno- } \\
\text { orbital / } \\
\text { Frontal } \\
\text { convexity }\end{array}$ & $\begin{array}{l}\text { Parietal } \\
\text { convexity }\end{array}$ & $\begin{array}{l}\text { Frontal and } \\
\text { parietal } \\
\text { convexity }\end{array}$ \\
\hline $\begin{array}{l}\text { WHO grade } \\
\text { (I/II/III) }\end{array}$ & NA & $\begin{array}{l}\text { Grade I } \\
\text { Fibro- } \\
\text { blastic* }\end{array}$ & NA & NA \\
\hline $\begin{array}{l}\text { PR (low/ } \\
\left.\text { high }^{1}\right)\end{array}$ & NA & High* & NA & NA \\
\hline $\begin{array}{l}\text { Ki-67(\%) } \\
\left(\text { low/high }{ }^{2}\right)\end{array}$ & NA & Low* & NA & NA \\
\hline Mutation & NA & PIK3CA* & NA & NA \\
\hline $\begin{array}{l}\text { Meningeal } \\
\text { embryologi- } \\
\text { cal origin }\end{array}$ & Neural crest & $\begin{array}{c}\text { Paraxial } \\
\text { meso- } \\
\text { derm*/ } \\
\text { Neural } \\
\text { crest }\end{array}$ & Neural crest & Neural crest \\
\hline
\end{tabular}

${ }^{1} \mathrm{PR}$ positivity $>75 \%$

${ }^{2} \mathrm{Ki}-67 \%>10 \%$

*Only the spheno-orbital meningioma was analyzed

$\mathrm{PR}=$ progesterone receptors

Publisher's note Springer Nature remains neutral with regard to jurisdictional claims in published maps and institutional affiliations. 